05

\title{
Зависимость температуры сублимации образующихся в пламенах сажевых частиц от их размеров и структуры
}

\author{
(C) Е.В. Гуренцов, А.В. Дракон, А.В. Еремин, Р.Н. Колотушкин, Е.Ю. Михеева \\ Объединенный институт высоких температур РАН, \\ 125412 Москва, Россия \\ e-mail: gurentsov@ihed.ras.ru
}

Поступило в Редакцию 7 июля 2021 г.

В окончательной редакции 24 сентября 2021 г.

Принято к публикации 4 октября 2021 г.

Получена зависимость температуры сублимации сажевых частиц, синтезированных при горении различных углеводородов, в зависимости от их размера и структуры. В основе экспериментального подхода лежит анализ теплового излучения частиц, нагретых до температуры сублимации наносекундным лазерным импульсом. Температура сублимации сажевых частиц измерялась при помощи метода двулучевой пирометрии. Для сравнения данных в разных пламенах предложено использовать средний размер первичных частиц. Установлено, что температура сублимации сажевых частиц зависит в основном от стадии их формирования, которая характеризуется ростом средних размеров. В работе показано, что при увеличении средних размеров частиц от 12 до $23 \mathrm{~nm}$ их температура сублимации увеличивается от 2700 до $4500 \mathrm{~K}$. Это отражает существенное различие термодинамических и оптических свойств так называемых „молодых“ и „взрослых“ частиц сажи, которое необходимо учитывать при разработке методов диагностики сажи и при теплофизическом анализе процессов горения и пиролиза с образованием сажи.

Ключевые слова: пламена, сажевые частицы, температура сублимации, структура сажевых частиц, просвечивающая электронная микроскопия, лазерно-индуцированная инкандесценция.

DOI: $10.21883 /$ JTF.2022.01.51855.206-21

\section{Введение}

Сажа представляет собой аморфный наноуглерод, состоящий из „первичных“ сферических углеродных наночастиц, объединенных в агрегаты фрактальной структуры. Каждая первичная частица размером 5-50 nm состоит из хаотично соединенных кристаллитов, в свою очередь представляющих собой стопки графеновых плоскостей размером порядка $1 \mathrm{~nm}[1,2]$. Общий механизм образования сажи детально описан в работе [3]. Процесс образования сажи при горении и пиролизе углеводородов можно разделить на три стадии. На первой стадии под действием высокой температуры (до $2000^{\circ} \mathrm{C}$ ) происходит пиролиз углеводородов, который приводит к образованию более мелких промежуточных продуктов для образования первого ароматического кольца с последующим добавлением других ароматических и алкильных соединений с образованием полиароматических углеводородов (ПАУ) с количеством атомов углерода 25-40 [4,5]. В соответствии с наиболее признанными представлениями читается, что образование ПАУ происходит по механизму НАCA (абстрагирование $\mathrm{H}$, добавление $\mathrm{C}_{2} \mathrm{H}_{2}$ ) [6]. На второй стадии происходит образование зародышей сажевых частиц. В настоящее время отсутствует общепризнанный механизм образования сажевых зародышей. Известно, что зародышами являются очень маленькие частицы, диаметр которых не превышает $1-3 \mathrm{~nm}[4,7]$. Одной из гипотез образования зародышей является объединение крупных полиарома- тических молекул в стопки (так называемые кристаллиты) [4]. Стадия образования зародышей определяет основные показатели сажевого аэрозоля. На третьей стадии сажевые частицы растут из зародышей при их агломерации и за счет гетерогенных реакций на их поверхности [3].

Знание термодинамических свойств сажевых частиц необходимо для развития методов диагностики сажи, для расчетов теплообмена в камерах сгорания, котлах и других устройствах, связанных с сажеобразованием. Теоретический анализ термодинамических свойств сажевых частиц затруднен, поскольку их внутренняя структура существенно неоднородна и может изменяться от полностью аморфной, состоящей из неупорядоченных графеновых плоскостей (протяженностью до $2-3 \mathrm{~nm}$ ) до частично кристаллической, когда графеновые слои образуют так называемые кристаллиты - стопки из нескольких параллельных плоскостей с межплоскостным расстоянием несколько большими, чем в чистом графите $(0.335 \mathrm{~nm})$ [8]. Кристаллиты с различной степенью упорядоченности образуют сферические первичные сажевые частицы со средними размерами $10-30 \mathrm{~nm}$. Таким образом, экспериментальные методы имеют решающее значение для исследования термодинамических свойств различных сажевых частиц.

В ряде работ [9-12] показано, что оптические свойства сажевых частиц существенно изменяются по высоте пламени. Высота над срезом горелки в пламенах является аналогом времени реакции в реакторах постоянного объ- 
ема, например, в ударной трубе [13]. Логично предположить, что термодинамические свойства сажевых частиц, образующихся в пламенах, также зависят от стадии их образования и от вида используемого углеводородного топлива.

Температура сублимации является важным термодинамическим свойством сажевых частиц. Ее знание может быть использовано для определения всей совокупности термодинамических свойств [14]. Для нагрева сажевых частиц до температуры сублимации обычно используется воздействие импульсным лазерным излучением на длине волны $1064 \mathrm{~nm}$. Возникающее при импульсном лазерном воздействии тепловое излучение (инкандесценция) намного интенсивнее излучения пламени и может быть использовано для определения текущей температуры сажевых частиц $[15,16]$. Температура сублимации определяется путем измерения максимальной температуры лазерно-нагретых сажевых частиц в зависимости от плотности энергии лазерного излучения. При достижении порога сублимации сажевых частиц при плотности энергии лазера $0.1-0.2 \mathrm{~J} / \mathrm{cm}^{2}$ (при импульсе лазера длительностью 5-10 ns на длине волны $1064 \mathrm{~nm}$ ) максимальная температура нагрева частиц перестает расти и выходит на плато, что говорит о протекании процесса фазового перехода. Дополнительно протекание процесса сублимации наночастиц при лазерном нагреве зафиксировано при исследовании пиролиза углеводородов в ударной трубе методом лазерной экстинкции $[13,17,18]$. Таким образом, лазерно-индуцированная инкандесценция (ЛИИ) является перспективным методом для исследования теплофизических свойств наночастиц. Известные к настоящему времени измерения температуры сублимации сажевых частиц, измеренные при помощи метода ЛИИ, представлены в обзоре [19]. Исследования углеродных наночастиц, синтезированных при пиролизе углеводородов в ударной трубе [13,17], показали, что температура сублимации увеличивается от 2700 до $3300 \mathrm{~K}$ при увеличении размеров частиц от 2 до $12 \mathrm{~nm}$. Кроме того, температура сублимации сильно зависела от температуры за ударной волной.

В отличие от ударно-трубных экспериментов в пламенах исследования температуры сублимации сажевых частиц проводились в основном с их привязкой к высоте пламени, при этом размер частиц не всегда был измерен.

Разнообразие термодинамических свойств частиц сажи, как и разнообразие их оптических свойств, очевидно, связано с особенностями их внутреннего строения [20]. В последнее десятилетие частицы сажи различной структуры были исследованы с помощью просвечивающей электронной микроскопии высокого разрешения (ПЭМ ВР), которая позволяет определять структурные параметры „каркаса“ частиц сажи, состоящего из отдельных полос (графеновых плоскостей, видимых с торца как полосы). К таким параметрам относятся длина графеновой плоскости, кривизна графеновой плоскости и межплоскостное расстояние [21].
Целью настоящей работы являлось определение температуры сублимации сажевых частиц в пламенах этилен/воздух, ацетилен/воздух и пропилен/воздух в зависимости от их размеров и поиск корреляции этой зависимости с параметрами внутренней структуры и размера частиц.

\section{1. Методы исследования}

\section{1. Горелка}

Эксперименты в пламенах предварительно перемешанных газов проводились с использованием стандартной горелки плоского пламени типа Мак-Кенна (Holthuis $\&$ Associates) с пористой поверхностью из бронзы, диаметром $62 \mathrm{~mm}$ (рис. 1). Для стабилизации пламени использовался латунный диск диаметром $60 \mathrm{~mm}$ и толщиной $20 \mathrm{~mm}$, расположенный на высоте $23 \mathrm{~mm}$ над срезом горелки (для пламени пропилен/воздух на высоте $30 \mathrm{~mm}$ ). Горелка имела внешний кольцевой контур для подачи потока газа для дополнительной стабилизации пламени. В настоящей работе для этого использовался воздух из компрессора. Когда соотношение топлива и окислителя больше стехиометрического, часть топлива расходуется на нагрев газа, а при пиролизе оставшегося топлива происходит формирование сажевых частиц. В приближении одномерной структуры плоского пламени мольные доли веществ и температура изменяются только в зависимости от высоты над поверхностью горелки. В настоящих экспериментах исследовались пламена этилен/воздух: $\mathrm{C}_{2} \mathrm{H}_{4}-14.08 \% ; \quad \mathrm{O}_{2}-18.05 \% ; \quad \mathrm{N}_{2}-67.87 \%$ с соотношением $\mathrm{C} / \mathrm{O}=0.78$; ацетилен/воздух: $\mathrm{C}_{2} \mathrm{H}_{2}-13.28 \%$; $\mathrm{O}_{2}-18.45 \% ; \mathrm{N}_{2}-68.27 \%$ с соотношением $\mathrm{C} / \mathrm{O}=0.72$;

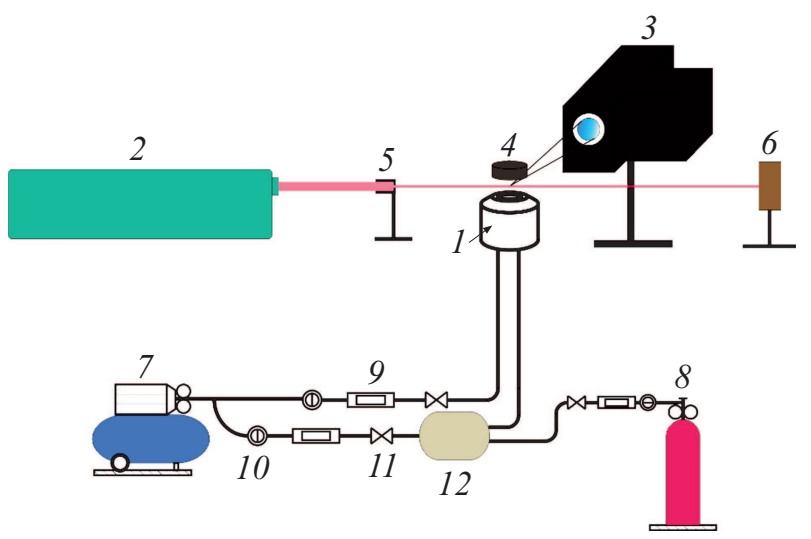

Рис. 1. Схема экспериментальной установки на базе горелки плоского пламени предварительно перемешанных газов: 1 - горелка, $2-\mathrm{Nd}$ :YAG-лазер, $3-$ прибор для измерения ЛИИ сигналов с двумя фотоумножителями, снабженными фильтрами с центрами 450 и $670 \mathrm{~nm}, 4$ - стабилизатор пламени, 5 - диафрагма, 6 - измеритель энергии лазера, 7 - воздушный компрессор, 8 - баллон с углеводородом, 9 - расходомеры, $10-$ фильтры, $11-$ вентили, $12-$ камера смешения. 
пропилен/воздух: $\mathrm{C}_{3} \mathrm{H}_{6}-11.2 \% ; \mathrm{O}_{2}-18.6 \% ; \mathrm{N}_{2}-70.2 \%$ с соотношением $\mathrm{C} / \mathrm{O}=0.9$. Расходы газов контролировали с помощью регуляторов массового расхода РРГ-10 (Элточприбор). Для измерений температуры по высоте пламени использовались платино-родиевые термопары типа В с диаметром проволоки $45 \mu \mathrm{m}$ и диаметром спая $70 \mu \mathrm{m}$. Реальная температура газа оценивалась с учетом конвективных и радиационных потерь тепла в пламени и с учетом отложения сажевых частиц на спае термопары по методике [22]. Для нагрева сажевых частиц использовалось излучение Nd:YAG-лазера LQ-215 (SOLAR Laser Systems) на длине волны 1064 nm. Регистрация сигналов ЛИИ производилась на двух длинах волн с помощью двух фотоумножителей H6780-20 (время нарастания сигнала $0.78 \mathrm{~ns}$ ). Модули были оснащены узкополосными фильтрами с центрами на длинах волн 450 и $670 \mathrm{~nm}$. Сигналы регистрировались с помощью осциллографа LeCroy WavePro 7100 с полосой пропускания $1 \mathrm{GHz}$.

\section{2. Измерение температуры сублимации сажевых частиц}

Измерение максимальной температуры лазернонагретых частиц сажи производилось при помощи метода двулучевой пирометрии. Для этого измерение максимальной амплитуды сигналов ЛИИ проводилось на двух длинах волн 450 и $670 \mathrm{~nm}$ в видимом диапазоне спектра. На рис. 2 показан пример зарегистрированных сигналов ЛИИ в зависимости от времени в пламени ацетилен/воздух на высоте $17 \mathrm{~mm}$. В течение времени лазерного импульса $(6 \mathrm{~ns})$ сигнал ЛИИ достигает максимального значения из-за повышения температуры частиц, а затем после окончания лазерного импульса спадает при падении температуры.

Так как спектральная плотность излучения частиц сажи описывается законом Планка, значение их текущей

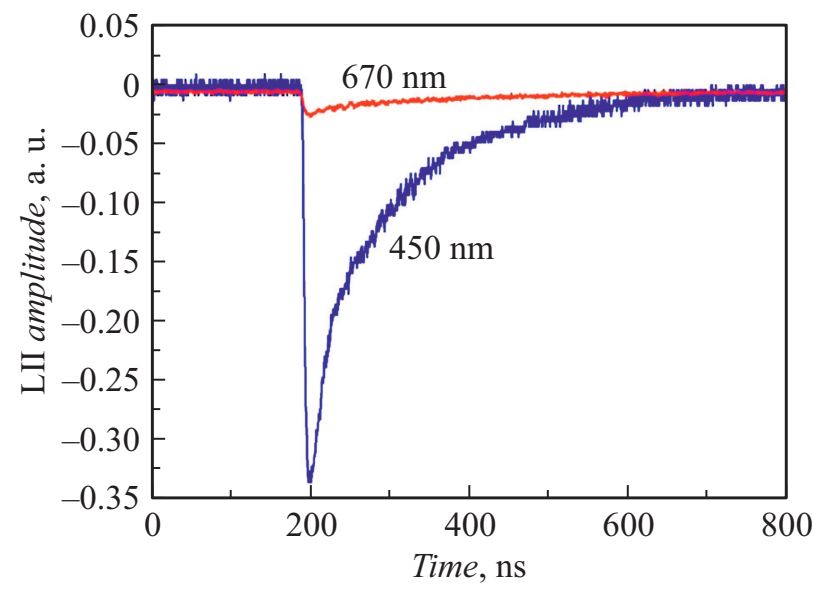

Рис. 2. Пример зарегистрированных сигналов ЛИИ в зависимости от времени в пламени ацетилен/воздух на высоте $17 \mathrm{~mm}$ при плотности энергии лазерного излучения $0.13 \mathrm{~J} / \mathrm{cm}^{2}$.

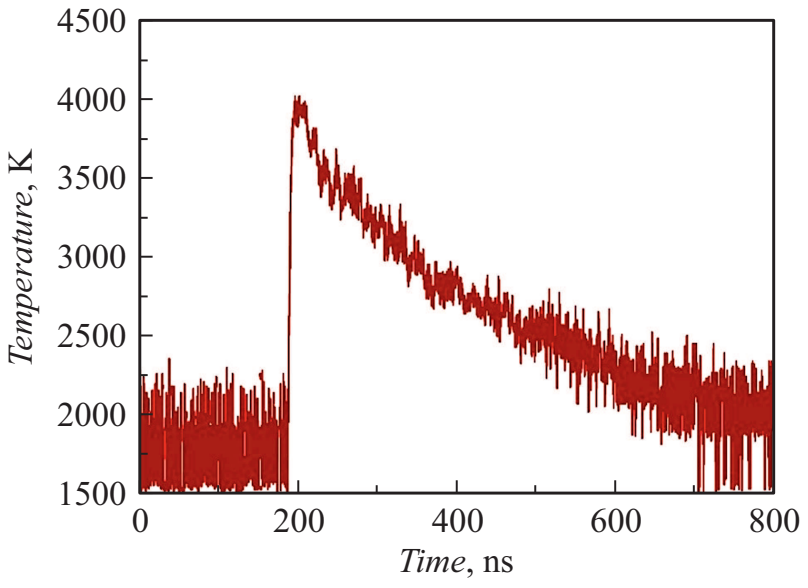

Рис. 3. Пример временного профиля температуры лазернонагретых частиц сажи, синтезированных в пламени ацетилен/воздух на высоте $17 \mathrm{~mm}$ при плотности энергии лазерного излучения $0.13 \mathrm{~J} / \mathrm{cm}^{2}$.

температуры может быть выражена как в [23]:

$$
\begin{aligned}
& T_{p}=\frac{h c}{k_{\mathrm{B}}} \\
& \times \frac{\left(1 / \lambda_{2}-1 / \lambda_{1}\right)}{\ln \left(S_{1} S_{B B 2} \varepsilon\left(\lambda_{2}\right) / S_{2} S_{B B 1} \varepsilon\left(\lambda_{1}\right)\right)+h c / k_{\mathrm{B}} T_{B B}\left(1 / \lambda_{2}-1 / \lambda_{1}\right)},
\end{aligned}
$$

где $h$ - постоянная Планка, $c$ - скорость света в вакууме, $k_{\mathrm{B}}$ - постоянная Больцмана, $S_{1}, S_{2}-$ максимумы амплитуд сигналов ЛИИ на длинах волн $\lambda_{1}$ и $\lambda_{2}, S_{B B 1}$ и $S_{B B 2}$ - амплитуды сигналов от источника излучения с известной температурой, $T_{B B}$ - температура источника, $\varepsilon\left(\lambda_{1,2}\right)$ - излучательные способности частиц на длинах волн наблюдения $\lambda_{1}$ и $\lambda_{2}$. Для определения излучательной способности наночастиц в пределе Рэлея (размер частиц много меньше длины волны) используется выражение [24]:

$$
\varepsilon(\lambda)=\frac{4 \pi d_{p} E(m)}{\lambda} .
$$

В выражении (2) $d_{p}-$ средний размер первичных сажевых частиц, $E(m)-$ функция коэффициента преломления $(m=n-i k)$ сажевых частиц,

$$
E(m)=-\operatorname{Im}\left(\frac{m^{2}-1}{m^{2}+2}\right)=\frac{6 n k}{\left(n^{2}-k^{2}+2\right)^{2}+4 n^{2} k^{2}} .
$$

Для корректного определения отношения излучательных способностей сажевых частиц на длинах волн 450 и $670 \mathrm{~nm}$ использовались измеренные в работах $[11,12]$ величины отношения $E(m, 1064) / E(m, 532)$ для длин волн 1064 и $532 \mathrm{~nm}$ в соответствуюших пламенах для каждой высоты пламени в предположении линейной зависимости $E(m)$ от длины волны. Пример временного профиля температуры лазерно-нагретых частиц сажи, синтезированных в пламени ацетилен/воздух на высоте $17 \mathrm{~mm}$, представлен на рис. 3. Из рисунка видно, 


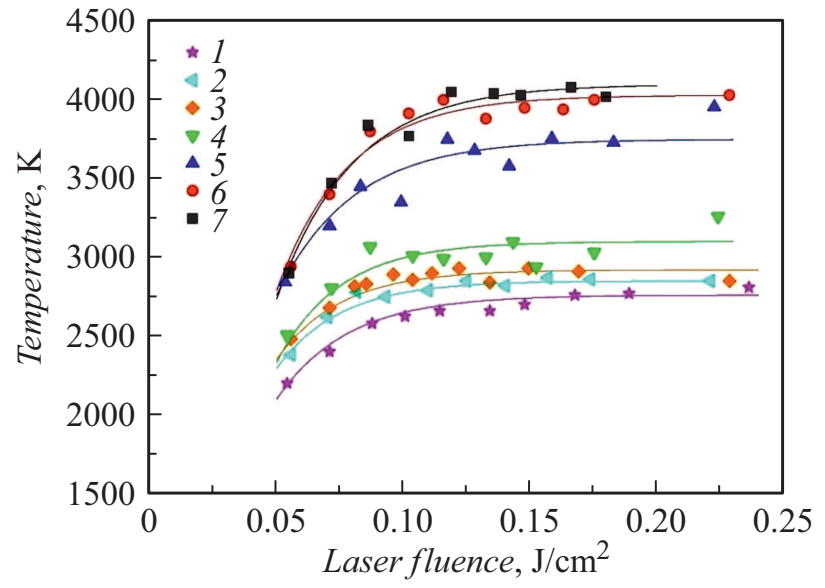

Pис. 4. Максимальные температуры лазерного нагрева сажевых частиц, синтезированных в пламени ацетилен/воздух, измеренные методом двулучевой пирометрии, в зависимости от плотности энергии лазера. Высота над срезом горелки: $1-5,2-7,3-10,4-13,5-15,6-17,7-20 \mathrm{~mm}$. Линии - аппроксимация экспериментальных данных.

что максимальная температура частиц при лазерном нагреве в данных условиях достигает $4000 \mathrm{~K}$, существенно превышая температуру пламени (1500-1800 K), измеренную при помощи термопары.

На рис. 4 представлены максимальные температуры лазерного нагрева наночастиц, синтезированных в пламени ацетилен/воздух, измеренные методом двулучевой пирометрии, в зависимости от плотности энергии лазера. Из рисунка видно, что максимальные температуры лазерно-нагретых сажевых частиц увеличиваются с увеличением плотности энергии лазера от 0.05 до $0.1 \mathrm{~J} / \mathrm{cm}^{2}$ в результате увеличения поглощенной частицами энергии. При плотностях энергии лазера менее $0.05 \mathrm{~J} / \mathrm{cm}^{2}$ малое отношение сигнал/шум не позволяло корректно измерять температуру двулучевым методом в данных условиях. Максимальные температуры сажевых частиц не изменялись при увеличении плотности энергии лазерного излучения больше $0.1 \mathrm{~J} / \mathrm{cm}^{2}$, что интерпретировалось как протекание процесса фазового перехода (сублимации сажи) при данной температуре, и было подтверждено измерениями резкого падения объемной фракции конденсированной фазы в момент воздействия лазерного импульса в ударно-трубном реакторе $[13,17]$. Из рассмотрения рис. 4 видно, что температура сублимации зависит от высоты над срезом горелки, соответствующим различным стадиям роста сажевых частиц или различному времени реакции. При этом температура сублимации на высотах 5-13 mm оказывается существенно ниже температуры сублимации сажи, сформировавшейся на высотах 15-20 mm. Данное отличие может быть обусловлено существованием на этих высотах так называемой „молодой“ и „взрослой“ сажи соответственно, оптические и теплофизические свойства которых также существенно отличаются [25-28]. Погрешность определенной таким образом температуры сублимации сажевых частиц оценивается как $\pm 4 \%$.

\section{3. Просвечивающая электронная микроскопия}

Для анализа средних размеров и структуры частиц сажи использовалась просвечивающая электронная микроскопия (ПЭМ). Образцы частиц помещали на медные решетки для электронной микроскопии, покрытые микродырчатым углеродным монослоем. Для взятия образцов из пламени решетки устанавливались в держателе с механическим пневмоприводом для его кратковременного введения в пламя на определенной высоте над срезом горелки. Время экспозиции решетки в пламени составляла $100 \mathrm{~ms}$. Образцы частиц анализировали на просвечивающем электронном микроскопе FEI Osiris c ускоряющим напряжением $200 \mathrm{kV}$ в Федеральном исследовательском центре кристаллографии и фотоники РАН.

Микрофотографии низкого разрешения использовались для построения распределений по размерам первичных частиц сажи, полученных в трех исследованных пламенах, в зависимости от высоты над срезом горелки. Для построения каждого распределения использовалось более тысячи измерений первичных частиц. Средние размеры частиц были определены при помощи аппроксимации полученного распределения лог-нормальной функцией. На рис. 5 представлены зависимости средних размеров частиц сажи от высоты пламени. На более низких высотах не удалось собрать достаточно материала для анализа методом ПЭМ.

Рис. 5 позволяет определить области бессажевого и сажевого пламени для исследованных условий. Наименьшие размеры частиц сажи соответствовали высотам над срезом горелки, меньше которых не удавалось получить образцы сажи с дискретизацией $1 \mathrm{~mm}$ по высоте (,минимальным“ высотам). Бессажевая зона, визуально видимая в голубом цвете, для пламени этилен/воздух находи-

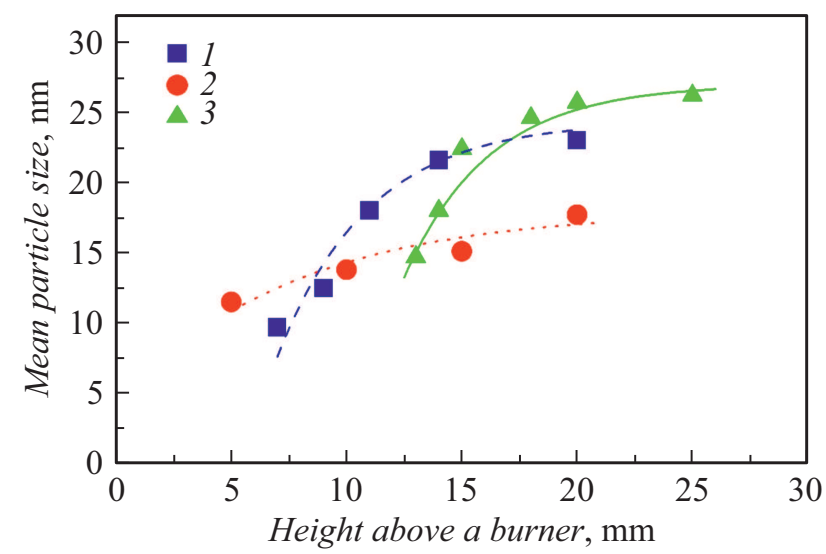

Рис. 5. Средние размеры частиц сажи в зависимости от высоты для пламен: 1 - этилен/воздух, 2 - ацетилен/воздух, 3 - пропилен/воздух. Кривые - аппроксимация экспериментальных данных методом наименьших квадратов. 


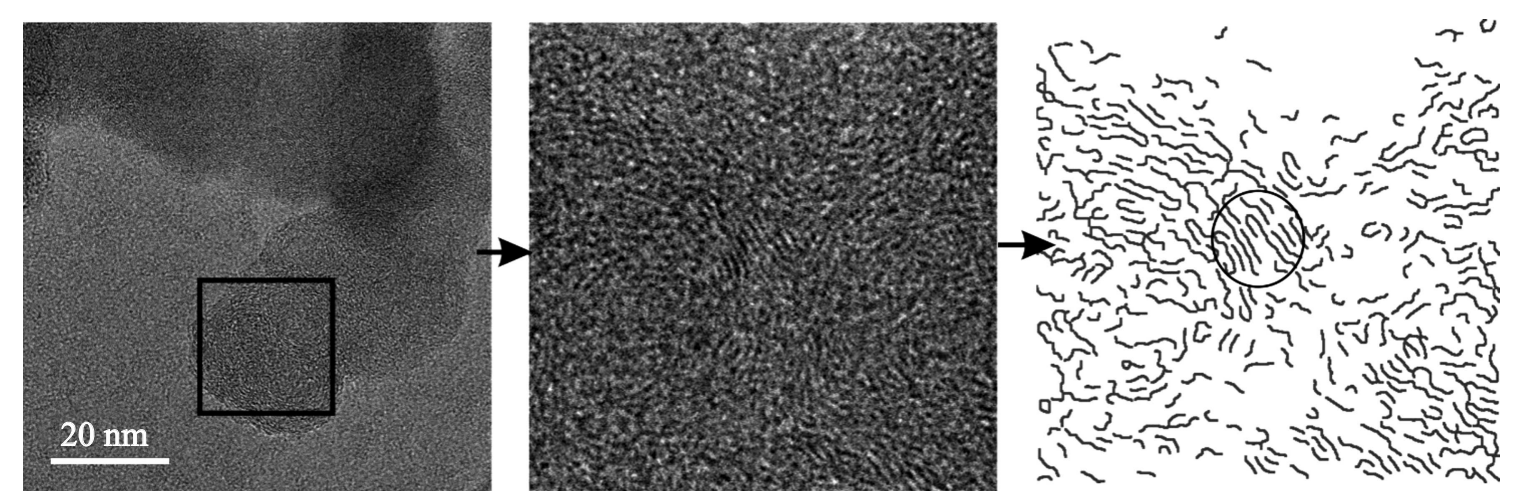

Рис. 6. Преобразование изображения высокого разрешения в скелетонизированную структуру сажевой частицы, содержащей кристаллиты. Образец взят на высоте $20 \mathrm{~mm}$ в пламени пропилен/воздух.

лась на высоте 0-6 mm, для пламени ацетилен/воздух на высоте 0-4 mm и для пламени пропилен/воздух на высоте 0-12 mm. Соответственно выше находились сажевые области (визуально определяемые желтым цветом). Таким образом, на высотах 6-7 mm для пламени этилен/воздух, 4-5 mm для пламени ацетилен/воздух и 12-13 mm для пламени пропилен/воздух происходит резкий рост размеров сажевых частиц, после чего размеры первичных частиц сажи с высотой изменяются более плавно, выходя примерно на постоянный уровень, после которого увеличиваются только размеры агрегатов.

Для определения параметров внутренней структуры первичных частиц сажи использовались микрофотографии высокого разрешения. Алгоритм анализа изображений ПЭМ высокого разрешения был описан ранее $[29,30]$. Обработка изображений проводилась с помощью программы анализа изображений ImageJ. Процедура обработки включала этап выделения характерного участка структуры сажи на ПЭМ-изображении высокого разрешения. Выбранные области изображения были сохранены как 8-битные полутоновые изображения размером $512 \times 512$ пикселей. Необработанные оцифрованные изображения были преобразованы при помощи быстрого преобразования Фурье и отфильтрованы с использованием кольцевых масок с размерами $0.335 \mathrm{~nm}$ (расстояние между графитовыми слоями) и $0.7 \mathrm{~nm}$ (при которых силы Ван-дер-Ваальса между двумя слоями можно считать незначительными). После обратного преобразования мелкие детали изображения игнорируются. Отфильтрованное изображение преобразовывалось в бинарное черно-белое изображение путем установки порогового значения яркости для фазовой границы. Полученное изображение скелетонизировалось путем сжатия темных областей, пока они не станут шириной в один пиксель. Каждая отдельная полоса рассматривается как независимый объект - графеновая плоскость, видимая с торца. Полосы менее $0.25 \mathrm{~nm}$ были исключены, поскольку это значение соответствует размеру только одного ароматического кольца. Скелетонизированные изображения позволяли проводить статистические измерения длины, кривизны (отношение длины полосы к прямому расстоянию между концами полосы) и межплоскостного расстояния между параллельными полосами внутри структуры частиц сажи. На рис. 6 показан пример преобразования изображения ПЭМ высокого разрешения в структуру углеродного скелета сажевой частицы для образца сажи, взятого в пламени пропилен/воздух на высоте $20 \mathrm{~mm}$, которая соответствует заключительному этапу сажеобразования. Область, содержащая кристаллиты, выделена кружком.

\section{2. Результаты и обсуждение}

На рис. 7 приведены полученные с помощью описанного выше метода двулучевой пирометрии температуры сублимации сажевых частиц, синтезированных в пламенах пропилен/воздух, этилен/воздух и ацетилен/воздух в зависимости от их среднего размера, измеренного при статистической обработке микрофотографий, сделанных при помощи электронной микроскопии низкого разрешения. Для сравнения на рис. 7 нанесены аналогичные данные, полученные в работе [9] в плоском пламени предварительно перемешанных газов этилен/воздух с использованием аналогичной горелки, но при другом соотношении горючее/окислитель. Превышение соотношения горючее/окислитель над стехиометрическим в работе [9] составляло 2.1, в отличие от величины 2.34, использованной в настоящей работе для этилено/воздушного пламени. Необходимо отметить, что в работе [9] температуры сублимации сажевых частиц были исследованы в зависимости от высоты над срезом горелки, а их средние размеры были получены с помощью метода ПЭМ. Дополнительно на рис. 7 нанесен результат измерения температуры сублимации частиц сажи со средним размером $33 \mathrm{~nm}$, синтезированных в стандартном этиленовом диффузионном пламени [31]. Из рассмотрения рис. 7 видно, что температура сублимации сажевых частиц существенно растет от значений 2500 до $4500 \mathrm{~K}$ при увеличении размера частиц от 8 до $20 \mathrm{~nm}$. В исследованных атмосферных 


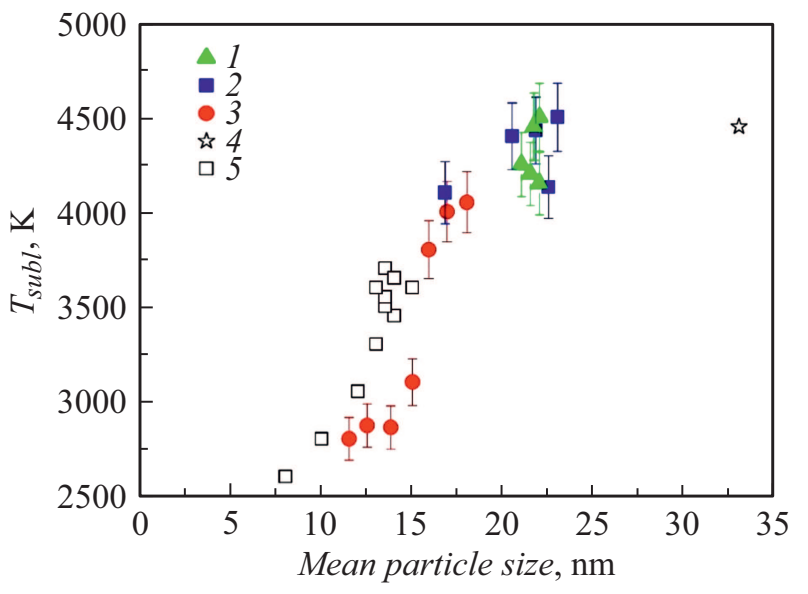

Рис. 7. Температура сублимации сажевых частиц, синтезированных в различных пламенах в зависимости от их среднего размера: 1 - пламя предварительно перемешанных газов пропилен/воздух (настоящая работа), 2 - пламя предварительно перемешанных газов этилен/воздух (настоящая работа), 3 - пламя предварительно перемешанных газов ацетилен/воздух (настоящая работа), 4 - диффузионное ламинарное этиленовое пламя [31], 5 - пламя предварительно перемешанных газов этилен/воздух [9].

пламенах предварительно перемешанных газов частицы с размерами менее $7 \mathrm{~nm}$ трудно зарегистрировать методом электронной микроскопии, так как происходит их быстрый рост до этого размера в диапазоне 1-2 mm по высоте пламени, что не позволяет собрать образцы частиц разных размеров. Кроме того, чем меньше размер частиц, тем меньше по количеству их удается собрать на решетку для электронного микроскопа, что не позволяет провести полноценную статистическую обработку.

Сажевые частицы с размерами больше $23 \mathrm{~nm}$ в плоских пламенах предварительно перемешанных газов не удается собрать из-за прекращения процесса сажеобразования при установке стабилизатора пламени, позволяющего добиться однородности параметров пламени по высоте. Как правило, такой стабилизатор устанавливается на высоте от 10 до $30 \mathrm{~mm}$. В диффузионных пламенах сажевые частицы вырастают до больших размеров из- за отсутствия тела, ограничивающего высоту пламени. Таким образом, после интенсивного роста температуры сублимации сажевых частиц в диапазоне размеров 8-20 nm наблюдается ее стабилизация в диапазоне 4250-4450 K. Это можно объяснить тем, что внутренняя структура частиц сажи и соответственно ее теплофизические свойства не изменяются при достижении размеров около $20 \mathrm{~nm}$. В то же время в диапазоне размеров 8-20 nm можно предположить существенное изменение термодинамических и оптических свойств сажевых частиц. Отметим, что размеры частиц в пламени пропилен/воздух находятся в диапазоне размеров 20-22 nm. Это связано с тем, что в данном пламени граница областей бессажевого (голубого) и сажевого (желтого) пламени очень резкая, там быстро растет амплитуда ЛИИ сигналов, и на высотах, где размер частиц меньше $20 \mathrm{~nm}$, соотношение сигнал/шум не позволяет проводить корректные измерения температуры сублимации.

Стоит отметить, что в исследованных пламенах существенно отличалась температура. В пламени ацетилен/воздух на исследованных в настоящей работе диапазонах высот над срезом горелки она составляла $1800-1960 \mathrm{~K}$, в пламени этилен/воздух - 1350-1600 K и 950-1000 К в пламени пропилен/воздух. В работе [32] было исследовано различие в структуре сажевых частиц, формирующихся в пламени предварительно перемешанных газов метан/воздух при температурах 1650 и $1770 \mathrm{~K}$. Показано, что изменение структуры сажевых частиц, формирующихся в пламени предварительно перемешанных газов, больше зависит от характеристик топлива, чем от температуры пламени [26,32]. В настоящей работе исследования структуры сажевых частиц, синтезированных в пламенах разных углеводородов при соответственно разной температуре, показали более сильную корреляцию с размерами частиц, чем с видом топлива и температурой пламени. Таким образом, удалось установить зависимость температуры сублимации сажевых частиц от их средних размеров, независимо от высоты в пламени, несмотря на различные используемые параметры пламен и вида углеводородов, использующихся для их синтеза.

Как было отмечено ранее, термодинамические свойства сажевых частиц должны коррелировать с изменениями в их внутренней структуре [27]. Используя данные, полученные при помощи анализа структуры сажевых частиц, извлеченные на различных стадиях их роста в пламенах, можно найти корреляцию их структуры и температуры сублимации. При статистической обработке изображений образцов были определены параметры структуры сажевых частиц: средняя длина графеновых плоскостей, средняя кривизна графеновых плоскостей и среднее расстояние между параллельными графеновыми плоскостями в кристаллитах для всех исследованных типов пламен и высот над срезом горелки, и построены зависимости этих параметров от среднего размера сажевых частиц. Было установлено, что средняя длина графеновых плоскостей исследованных сажевых частиц составляет порядка $1.2 \pm 0.1 \mathrm{~nm}$ и практически не зависит от их среднего размера. Результаты измерений демонстрируют незначительное уменьшение средней кривизны графеновых плоскостей от 1.4 до 1.3 при росте сажевых частиц в диапазоне $10-25 \mathrm{~nm}$. Сомнительно, чтобы такое небольшое изменение кривизны графеновых плоскостей в структуре сажевых частиц могло быть причиной наблюдаемых изменений их температуры сублимации.

Последним рассматриваемым параметром структуры сажевых частиц является среднее расстояние между параллельными графеновыми плоскостями, которые составляют участки кристаллической структуры внутри 


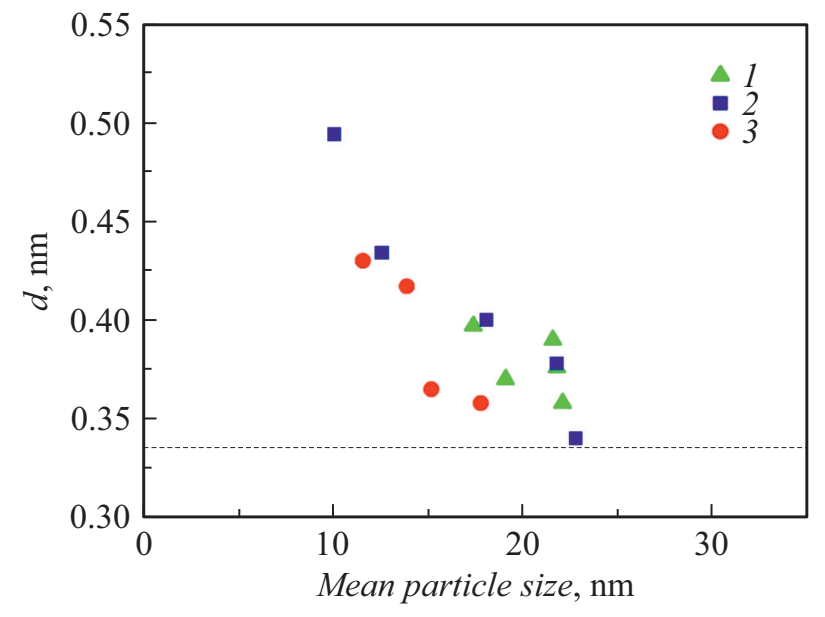

Рис. 8. Среднее расстояние между графеновыми плоскостями в сажевых частицах в зависимости от среднего размера сажевых частиц. Сажевые частицы получены: 1 - в пламени пропилен/воздух, 2 - в пламени этилен/воздух, 3 - в пламени ацетилен/воздух.

частицы, отмеченные на рис. 6. На рис. 8 средние межплоскостные расстояния представлены в зависимости от среднего размера сажевых частиц, синтезированных в настоящей работе при горении пропилена, этилена и ацетилена. Из рассмотрения рис. 8 можно увидеть тенденцию существенного сокращения межплоскостного расстояния от $0.5 \mathrm{~nm}$ до значения $0.35 \mathrm{~nm}$, близкого к межплоскостному расстоянию в графите $(0.335 \mathrm{~nm})$ при росте средних размеров сажевых частиц от 10 до $25 \mathrm{~nm}$. Таким образом, среди рассматриваемых параметров структуры сажевых частиц межплоскостное расстояние является параметром, коррелирующим с поведением температуры сублимации в том же диапазоне размеров сажевых частиц. Можно заключить, что при уменьшении среднего расстояния между параллельными графеновыми плоскостями в структуре сажевых частиц их температура сублимации увеличивается от 2500 до $4500 \mathrm{~K}$. Кроме того, при анализе микрофотографий высокого разрешения можно отметить, что увеличение среднего размера сажевых частиц сопровождается увеличением как количества кристаллитов в структуре сажевых частиц, так и количества параллельных графеновых плоскостей в них. На начальных стадиях роста сажевых частиц при их минимальных средних размерах до 10-12 nm в структуре редко встречается более двух параллельных графеновых плоскостей. Количество таких спаренных плоскостей в „молодых“ частицах тоже мало, и, таким образом, „молодую“ сажевую частицу можно охарактеризовать как объект с аморфной структурой. По мере роста сажевых частиц до средних размеров $20 \mathrm{~nm}$ и более, количество параллельных графеновых плоскостей в одном кристаллите увеличивается до 5 и более, при этом такие кристаллические области занимают все больший объем частицы, что приводит к тому, что до 50\% площади скелетонизированного изоб- ражения занимают кристаллические структуры. Уменьшение среднего межплоскостного расстояния качественно коррелирует с увеличением количества графеновых плоскостей в кристаллите и увеличением количества самих кристаллитов по мере роста сажи от „молодых“ до „взрослых“ частиц.

Необходимо отметить, что равновесная температура сублимации графита при атмосферном давлении составляет 3900-4000 K [33], при этом в составе паров преобладают кластеры $\mathrm{C}_{3}$ [34]. Максимальная же величина измеренной в настоящей работе температуры лазерной сублимации сажевых частиц $(4250-4450 \mathrm{~K})$ больше, чем равновесная температура сублимации кластеров $\mathrm{C}_{3}$ и хорошо согласуется с данными по равновесному испарению кластеров $\mathrm{C}_{2}(4457 \mathrm{~K})$ [35]. Эти данные показывают, что уменьшение температуры сублимации отражает процесс увеличения размера углеродных кластеров, отрываемых от частицы сажи в результате сублимации, что, в свою очередь, связано с ослаблением связей во внутренней структуре вследствие увеличения межплоскостного расстояния и уменьшением количества и размера кристаллитов, характеризующих процесс графитизации сажевых частиц по мере их роста. Соответственно изменение термодинамических свойств сажи прямо зависит от степени их графитизации. С другой стороны, чем „старше“ сажевая частица, тем плотней ее структура и тем труднее ее сублимировать (температура сублимации выше).

\section{Заключение}

В работе температура сублимации сажевых частиц определена методом двулучевой пирометрии с помощью измерения максимальной температуры лазернонагретых частиц сажи при варьировании плотности энергии лазера. Погрешность измерения температуры максимального лазерного нагрева составила $\pm 4 \%$. Средние размеры сажевых частиц и параметры их структуры были исследованы методом ПЭМ. Были получены значения температур сублимации и средних размеров сажевых частиц, синтезированных в пламенах этилен/воздух $(\mathrm{C} / \mathrm{O}=0.78)$, ацетилен/воздух $(\mathrm{C} / \mathrm{O}=0.72)$ и пропилен/воздух $(\mathrm{C} / \mathrm{O}=0.9)$. Впервые получены данные по зависимости температур сублимации сажевых частиц, сформировавшихся в пламенах предварительно перемешанных газов, от их средних размеров. Для пламени этилен/воздух температуры сублимации сажевых частиц увеличивались от 4100 до $4500 \mathrm{~K}$ при увеличении их средних размеров от 17 до $22 \mathrm{~nm}$. Для пламени ацетилен/воздух температуры сублимации сажевых частиц увеличивались от 2800 до $4100 \mathrm{~K}$ при увеличении их средних размеров от 12 до $19 \mathrm{~nm}$. Для пламени пропилен/воздух температуры сублимации сажевых частиц находились в диапазоне от 4100 до $4500 \mathrm{~K}$ при средних размерах 20-22 nm. Данные результаты показали, что в зависимости от стадии формирования сажевые частицы 
можно разделить на две группы: „молодые“ частицы с температурой сублимации 2800-3200 K и „взрослые“ частицы с температурой сублимации $3800-4500 \mathrm{~K}$, между которыми существует резкий переход в диапазоне средних размеров между 15 и $17 \mathrm{~mm}$. Наблюдаемое увеличение температуры сублимации сажевых частиц с ростом их средних размеров коррелирует с уменьшением межплоскостного расстояния между параллельными графеновыми плоскостями от 0.5 до $0.35 \mathrm{~nm}$, а также с увеличением количества расположенных рядом параллельных плоскостей и количества таких кристаллитов в структуре частицы.

\section{Благодарности}

Работа поддержана Российским научным фондом, грант № 19-79-10204.

\section{Конфликт интересов}

Авторы заявляют, что у них нет конфликта интересов.

\section{Список литературы}

[1] T. Ishiguro, Y. Takatori, R. Akihama. Combust. Flame, 108, 231 (1997). DOI: 10.16/S0010-2180(96)00206-4

[2] V. Fernandez-Alos, J.K. Watson, R. Vander Wal, J.P. Mathews. Combust. Flame, 158, 1807 (2011). DOI: $10.1016 /$ j.combustflame.2011.01.003

[3] B.S. Haynes, H.Gg. Wagner. Prog. Energy Combust. Sci., 7, 229 (1981). DOI: 10.1016/0360-1285(81)90001-0

[4] H. Wang. Proc. Combust. Inst., 33, 41 (2011). DOI: $10.1016 /$ j.proci.2010.09.009

[5] P. Desgroux, X. Mercier, K.A. Thomson. Proc. Combust. Inst., 34, 1713 (2013). DOI: 10.1016/j.proci.2012.09.004

[6] M. Frenklach. Phys. Chem. Chem. Phys., 4, 2028 (2002). DOI: 10.1039/B110045A

[7] L.A. Sgro, A.C. Barone, M. Commodo, A. D'Alessio, A. De Filippo, G. Lanzuolo, P. Minutolo. Proc. Combust. Inst., 32, 689 (2009). DOI: 10.1016/j.proci.2008.06.216

[8] M.L. Botero, Y. Sheng, J. Akroyd, J. Martin, J.A.H. Dreyer, W. Yang, M. Kraft. Carbon, 141, 635 (2019). DOI: 10.1016/j.carbon.2018.09.063

[9] H. Bladh, J. Johnsson, N.-E. Olofsson, A. Bohlin, P.E. Bengtsson. Proc. Combust. Inst., 33, 641 (2011). DOI: 10.1016/j.proci.2010.06.166

[10] S. Bejaoui, S. Batut, F. Therssen, N. Lamoureux, P. Desgroux, F. Liu. Appl. Phys. B, 118, 449 (2015). DOI: $10.1007 / \mathrm{s} 00340-015-6014-3$

[11] A.V. Eremin, E.V. Gurentsov, R.N. Kolotushkin. Appl. Phys. B, 126, 125 (2020). DOI: 10.1007/s00340-020-07426-3

[12] A.V. Drakon, A.V. Eremin, E.V. Gurentsov, E.Yu. Mikheyeva, R.N. Kolotushkin. Appl. Phys. B, 127, 81 (2021). DOI: $10.1007 / \mathrm{s} 00340-021-07623-8$

[13] Е.В. Гуренцов, А.В. Еремин, Е.Ю. Михеева. ТВТ, 55 (5) 737 (2017). DOI: 10.7868/S0040364416060077 [E.V. Gurentsov, A.V. Eremin, E.Yu. Mikheyeva. High Temperature, 55 (5), 723 (2017). DOI: 10.1134/S0018151X17040071]

[14] K.K. Nanda, A. Maisels, F.E. Kruis, H. Fissan, S. Stappert. Phys. Rev. Lett., 91, 106102 (2003).

DOI: 10.1103/PhysRevLett.91.106102
[15] S. De Iuliis, F. Migliorini, F. Cignoli, G. Zizak. Appl. Phys. B, 83, 397 (2006). DOI: 10.1007/s00340-006-2210-5

[16] D.R. Snelling, F. Liu, G.J. Smallwood, Ö.L. Gülder. Combust. Flame, 136, 180 (2004).

DOI:10.1016/j.combustflame.2003.09.013

[17] A. Eremin, E. Gurentsov, E. Mikheyeva, K. Priemchenko. Appl. Phys. B, 112, 421 (2013). DOI: $10.1007 / \mathrm{s} 00340-013-5530-2$

[18] Е.В. Гуренцов, А.В. Еремин, С.А. Мусихин. ЖТФ, 89 (8), 1200 (2019). DOI: 10.21883/JTF.2019.08.47891.2335 [E.V. Gurentsov, A.V. Eremin, S.A. Musikhin. Tech. Phys. 64, 1133 (2019). DOI: 10.1134/S1063784219080085]

[19] E. Gurentsov. Nanotechnol. Rev., 7 (6) 583 (2018). DOI: $10.1515 /$ ntrev-2018-0080

[20] C. Jager, Th. Henning, R. Schlogl, O. Spillecke. J. Non-Crystall. Sol., 258, 161 (1999). DOI: 10.1016/S0022-3093(99)00436-6

[21] V. Fernandez-Alos, J.K. Watson, R. Vander Wal, J.P. Mathews. Combust. Flame, 158, 1807 (2011). DOI: $10.1016 /$ j.combustflame.2011.01.003

[22] C.S. McEnally, Ü.Ö. Köylü, L.D. Pfefferle, D.E. Rosner. Combust. Flame, 109, 701 (1997). DOI: 10.1016/S0010-2180(97)00054-0

[23] B. Kock, C. Kayan, J. Knipping, H.R. Ortner, P. Roth. Proc. Combust. Inst., 30, 1689 (2004). DOI: $10.1016 /$ j.proci.2004.07.034

[24] H.A. Michelsen. J. Chem. Phys., 118, 7012 (2003). DOI: $10.1063 / 1.1559483$

[25] X. López-Yglesias, P.E. Schrader, H.A. Michelsen. J. Aerosol Sci., 75, 43 (2014). DOI: 10.1016/j.jaerosci.2014.04.011

[26] M. Alfe, B. Apicella, R. Barbella, J.N Rouzaud, A. Tregrossi, A. Ciajolo. Proc. Combust. Inst., 32, 697 (2009). DOI: $10.1016 /$ j.proci.2008.06.193

[27] H.A. Michelsen. Proc. Combust. Inst., 38, 1197 (2021) DOI: $10.1016 /$ j.proci.2020.06.383

[28] B. Apicella, P. Pré, J.N. Rouzaud, J. Abrahamson, R.L. Vander Wal, A. Ciajolo, A. Tregrossi, C. Russo. Combust. Flame, 204, 13 (2019). DOI: 10.1016/j.combustflame.2019.02.026

[29] H.-S. Shim, R.H. Hurt, N.Y.C. Yang. Carbon, 38, 29 (2000). DOI: $10.1016 / \mathrm{S} 0008-6223(99) 00096-2$

[30] A. Galvez, N. Herlin-Boime, C. Reynaud, C. Clinard, J-N. Rouzaund. Carbon, 40, 2775 (2002) DOI: $10.1016 / \mathrm{S} 0008-6223(02) 00195-1$

[31] F. Goulay, P.E. Schrader, X. Lopez-Yglesias, H.A. Michelsen. Appl. Phys. B, 112, 287 (2013). DOI: $10.1007 / \mathrm{s} 00340-013-5504-4$

[32] M. Alfe, B. Apicella, J.-N. Rouzaund, A. Tregrossi, A. Ciajolo. Combust. Flame, 157, 1959 (2010). DOI: 10.1016/j.combustflame.2010.02.007

[33] J. Abrahamson. Carbon, 12, 111 (1974). DOI: $10.1016 / 0008-6223(74) 90019-0$

[34] H.R. Leider, O.H. Krikorian, D.A. Young. Carbon, 11, 555 (1973). DOI: 10.1016/0008-6223(73)90316-3

[35] H.A. Michelsen, F. Liu, B.F. Kock, H. Bladh, A. Boiarciuc, M. Charwath, T. Dreier, R. Hadef, M. Hofmann, J. Reimann, S. Will, P.-E. Bengtsson, H. Bockhorn, F. Foucher, K.P. Geigle, C. Mounaïm-Rousselle, C. Schulz, R. Stirn, B. Tribalet, R. Suntz. Appl. Phys. B, 87, 503 (2007). DOI: $10.1007 / \mathrm{s} 00340-007-2619-5$ 